Power and Social Information Processing

\author{
Marianne Schmid Mast \\ Mahshid Khademi \\ Tristan Palese
}

Faculty of Business and Economics, University of Lausanne, Switzerland

\begin{abstract}
Author Note
Marianne Schmid Mast, Mahshid Khademi, and Tristan Palese, Department of Organizational Behaviour, Faculty of Business and Economics, University of Lausanne, Switzerland. Correspondence concerning this article should be addressed to Marianne Schmid Mast, Department of Organizational Behaviour, University of Lausanne UNIL- Chamberonne, Internef-619, CH-1015 Lausanne, Switzerland. Contact: Marianne.SchmidMast@unil.ch
\end{abstract}




\begin{abstract}
We review the scientific evidence concerning the relation between power and social information processing. Does having or obtaining power affect how we perceive and judge our social interaction partners and how accurately we do this? High power individuals perceive others as more agentic and tend to project characteristics of themselves onto others. People in power tend to stereotype others more and see them as less human and generally in a more negative way. Powerholders are not more or less accurate in assessing others; rather, the way they understand their power (as responsibility or opportunity) seems to make the difference: Power as responsibility results in better interpersonal accuracy. Our analysis shows that it is not so much being high or low in power that explains how we perceive others, but rather how we understand our power, whether our high power position is stable, and what our current interaction goals are.
\end{abstract}

Keywords: Power, status, social perception, stereotypes, interpersonal accuracy 


\section{Power and Social Information Processing}

Power affects powerholders themselves [1-3], how they are perceived by others [4], and how they interact with others [5]. In the present review article, we focus on power and social information processing, meaning on the effect that having or obtaining power has on powerholders' perception and interpretation of social stimuli. Social perception or social information processing is the study of how people form impressions and make inferences about their social interaction partners and whether these inferences are correct [6]. Social relationships can be characterized and classified along two perpendicular dimensions $[7,8]$ : The horizontal dimension describes interpersonal affiliation, closeness, or liking and the vertical dimension stands for power, control, or dominance. We ask whether being high on the vertical dimension of social relations (e.g., high power, high prestige, high status, or high dominance) $[5,9]$ affects the way the powerful perceive, judge, and make sense of their social interaction partners, whether they stereotype others more, and whether they perceive others more or less accurately. The purpose of this article is to answer these questions based on the existing empirical evidence to date.

\section{How do powerholders see others?}

Does having power affect how powerholders perceive their social interaction partners and what are the characteristics a powerholder is most interested in others? The approach/inhibition theory of power [10] suggests that high power individuals focus on rewards, which explains that they are more goal-oriented [11-13]. They might therefore be more interested in qualities of others that benefit goal-attainment. Agency, defined as being active, self-confident, and efficient in attaining goals [14], is such a quality. Indeed, high power individuals more so than low power individuals scrutinize others with respect to agency and prefer more agentic traits and less communal traits in others [15]. This is in line with research showing that powerholders tend to see others as means to an end $[16,17]$. 
Indeed, goal-orientation is linked to the objectification of others [18] and high power individuals are more likely to see their interaction partners as instrumental to their goals [16]. The objectification of others also shows in the fact that high power individuals dehumanize others. When taking drastic decisions concerning others, powerholders tend to dehumanize those affected [19]. In the same vein, high power individuals describe others as less uniquely human [20] and see others in a more negative way whereas they see themselves in a more positive way [17]. This effect was also confirmed in a meta-analysis showing a weighted mean $r$ of .29 between power and negative other-evaluation [21]. The powerholders' negative view of others shows also in that those in power belittle others by perceiving them as smaller [22] and by being less thankful to others for favors obtained, because those others are not seen as acting genuinely [23].

Another aspect of feeling powerful is that powerholders tend to see themselves in others. Given that powerful individuals are more focused on themselves, they anchor their judgments of others in themselves [24, 25]. To illustrate, participants with specific predispositions (i.e., dishonesty or extraversion), perceived social targets more in line with these traits when they were primed with high power as compared to when they were primed with low power. Similarly, high power individuals projected their competence (as opposed to their warmth) onto others [26]. And, when high power individuals judged the emotional states of others, these judgements were in line with the valence of their own emotional states [25]. However, when powerholders see their power position in jeopardy, emotion perception is not simply a projection of the powerholder's own feelings. Illegitimate powerholders are faster at identifying anger in others than legitimate ones [27]. In an instable power position, another person's anger can be seen as a threat, a signal of losing power, which is why illegitimate powerholders might be faster at tracking it. 
In sum, research suggests that people who have power perceive others through a lens of how those others can be beneficial for goal-attainment. This makes powerful people see others more as objects or even dehumanize them and evaluate them in a negative way. Also, high power individuals tend to project their traits and states onto others except when their power position is at stake; then, their social perception becomes functional in order to maintain their power (e.g., they are quick at identifying power threat from others via the latter's anger expression).

\section{Do powerholders stereotype others?}

People are motivated to identify with their in-group [28] and for people pertaining to high-power groups, this serves to keep their power and the privileges associated with their high status position. They should therefore be especially prone to stereotype outgroup members. This is in line with predictions of the Social Distance Theory of Power [29] stating that high power individuals put more distance between themselves and others and that stereotyping increases distance between the in- and the out-group [30].

The Continuum Model of Fiske and Neuberg [31] posits that social perception can be positioned on a continuum: A social interaction partner can be seen in an individualized/personalized way or simply as a representative of a social group (in a stereotypical way). The former would be equated with controlled cognition and the latter with automatic cognition. The approach/inhibition theory of power [10] predicts that power increases automatic social cognition, and powerlessness triggers controlled cognition. Fiske [32] argues that powerful individuals pay less attention to others (because less is at stake for them by ignoring others and because their attention is occupied by other demands) which favors automatic cognition and that is why they perceive others in a stereotypical way. Moreover, having high cognitive demands also puts the powerholder in "automatic cognition" mode, which activates implicit stereotypes $[33,34]$. For example, high power individuals 
show more automatic negative evaluations towards minority groups (i.e. Blacks and Arabs) [35] and are prone to more implicit stereotyping and prejudice [36]. Also, high power individuals pay more attention to stereotype-consistent information about other people (e.g., time reading adjectives describing a person) [37-39], and particularly to negative stereotypeconsistent information and especially when high status individuals feel threatened in their status (e.g., are illegitimate) [40].

In sum, powerholders seem to stereotype others more and maybe more so when their power position is not stable. But, does this mean that they perceive others less accurately as would be suggested by the Continuum Model [31]? The answer to this question is less straightforward than the model suggests.

\section{Are the powerful more or less accurate in perceiving others?}

Accurate perception of others (interpersonal accuracy) is a vast concept, defined as correctly assessing others' states and traits [41]. Sometimes, the correct recall of others' attributes is included in this definition.

Theoretical predictions state that high power individuals ought to be less accurate in perceiving others for many reasons: (1) because they use stereotypes more and accurate person perception requires paying attention to individuating information [10, 31], (2) because they are not motivated to attend to details differentiating people given that they are in power and have the control of the relevant resources [32], (3) because they have to deal with many subordinates and can therefore not attend to people individually because of cognitive load [32], (4) because they are self-focused and can afford being less interested in others [42], or (5) because power decreases the need to affiliate [43]. Despite the overwhelming number of arguments for why powerful people should be less accurate at assessing others, there are also several reasons for why the powerful might be more interpersonally accurate. For instance, contrary to predictions of the approach/inhibition theory, power has been shown to increase 
controlled cognition [44] and to the extent that this is what is needed to accurately assess others, the relation between power and interpersonal accuracy could be reversed. Also, one could argue that obtaining power increases a person's motivation to accurately decode their social interaction partners if they want to be successful in their power position or if they want to preserve their power. Research supports this argument by showing that leaders who are able to correctly assess others' emotions have more satisfied subordinates $[45,46]$ and obtain better performance ratings by their superiors [46]. Emotion recognition accuracy is related to better political skills, which then explains higher salaries [47]. Moreover, it is possible that people gain high power by using their interpersonal skills, meaning that interpersonal accuracy is an antecedent and not a consequence of power. This could explain why some studies find that people who are higher in a hierarchy in a given organization are more interpersonally accurate $[48,49]$ and that extraverts with better emotion recognition accuracy are more likely to emerge as leaders in a group [50].

It seems that being accurate in social perception is related to better outcomes for the high power person and his/her interaction partners. But what does the empirical evidence show with respect to the question of whether high or low power individuals are more interpersonally accurate? A meta-analysis [51] addressing the link between power (operationalized as either experimental manipulation such as role play or priming, social class, personality dominance, or achieved rank such as a given hierarchy position in a company) and interpersonal accuracy (operationalized as inferences about targets' traits or states or as recall of information about targets) found no overall effect for inference studies and a positive effect for recall studies, showing that high power people recall more information about others. Moreover, social class was positively related to accurate inferences about others. Maybe recalling more information about others is in line with perceiving others 
in an instrumental way in that the powerholder stores the information associated with other people in order to be able to use them for specific goals when needed.

Interestingly, in the aforementioned meta-analysis, there was evidence suggesting that how power was construed, affected the result: Personality dominance assessed as empathicresponsible dominance was positively linked to interpersonal accuracy whereas personality dominance as egoistic-aggressive dominance showed a negative (although not significant) relation to interpersonal accuracy. Sassenberg and colleagues [52] introduced the distinction between power as responsibility (towards others) and power as opportunity (to obtain more resources for oneself) in the realm of corruption. Using their terminology, we suggest that people who understand their power as responsibility have better interpersonal accuracy than people who understand their power as opportunity [53, Study 4].

How power is understood by the powerholder not only affects interpersonal accuracy but also perspective taking [54]. High-status individuals engage in more perspective taking than high-power individuals [55]. Status refers to how much prestige and respect an individual obtains from others whereas power means the position within a hierarchy [56]. Recently, it has also been suggested that psychological power, or sense of power, entails a sense of responsibility [57]. We see an analogy between power as responsibility and status in that people can only gain high status if they wield their power in a responsible way, in the interest of others. Indeed, research shows that status relates to treating others in a fairer way [58].

To understand the effect of power on interpersonal accuracy, there is more than one aspect of power that needs to be taken into account. Supporting this idea, accuracy in social network perception was not only a function of power, but also of formal (position in a firm's hierarchy) and informal (peer ratings of influence) hierarchical position and personality [59, 60]. And, social dominance orientation affected accurate emotion recognition such that high social dominance individuals were less accurate [61]. 
In sum, power per se does not seem to explain whether powerholders are accurate or not when perceiving others; rather, how power was conferred or obtained and how it is understood and interpreted by the powerholder determines whether others are seen accurately.

\section{Conclusion}

The question we need to ask is not how power affects social information processing but rather how the way power is experienced and interpreted by the powerholder and how other aspects such as legitimacy of power affect social perception and judgement. More broadly, the way power affects social perception depends on powerholders' personality and on situational cues and goals. If the powerholder's main concern is goal-attainment, others will be seen through the lens of how they can be useful to attain the goal [16]. If the powerholder's main concern is how to keep his/her power position (e.g., because of feeling illegitimate), others will be seen through the lens of being dangerous competitors [27] or as outgroup members that are stereotyped in order to keep them at bay [40]. If the powerholder's understanding of his/her power position is to feel responsible for others, he/she will become an expert in judging others' states and traits (i.e., interpersonal accuracy). To conclude, more than power per se, these proximal states determine how the powerful perceive their social interaction partners. 


\section{References}

Papers of particular interest are highlighted as:

*of special interest

**of outstanding interest

1. Fast NJ, Gruenfeld DH, Sivanathan N, Galinsky AD: Illusory control: A generative force behind power's far-reaching effects. Psychological Science 2009, 20:502-508.

2. Kraus MW, Chen S, Keltner D: The power to be me: Power elevates self-concept consistency and authenticity. Journal of Experimental Social Psychology 2011, 47:974-980.

3. Wojciszke B, Struzynska-Kujalowicz A: Power influences self-esteem. Social Cognition 2007, 25:472-494.

4. Fragale AR, Overbeck JR, Neale MA: Resources versus respect: Social judgments based on targets' power and status positions. Journal of Experimental Social Psychology 2011, 47:767-775.

5. Hall JA, Coats EJ, LeBeau LS: Nonverbal behavior and the vertical dimension of social relations: A meta-analysis. Psychological Bulletin 2005, 131:898-924.

** This is a comprehensive meta-analysis showing how different operationalizations of power are related to a large number of nonverbal cues and how those cues are related to perceived power or used to infer power in targets.

6. Higgins ET, Bargh JA: Social cognition and social perception. Annual Review of Psychology 1987, 38:369-425.

7. Kiesler DJ, Auerbach SM: Integrating measurement of control and affiliation in studies of physician-patient interaction: the interpersonal circumplex. Social Science Medicine 2003, 57:1707-1722. 
8. Wiggins JS: A psychological taxonomy of trait-descriptive terms: The interpersonal domain. Journal of Personality and Social Psychology 1979, 37:395412.

9. Schmid Mast M: Interpersonal behaviour and social perception in a hierarchy: The interpersonal power and behaviour model. European Review of Social Psychology 2010, 21:1-33.

** This review article presents a model including different aspects of power (e.g., status, dominance, states, and traits) of the target as well as the perception of the power of the social interaction partner and posits that interpersonal behavior and social perception is the result of all of those aspects of power and that there is no such thing as "power" in a void.

10. Keltner D, Gruenfeld DH, Anderson C: Power, approach, and inhibition. Psychological Review 2003, 110:265-284.

11. Galinsky AD, Gruenfeld DH, Magee JC: From power to action. Journal of Personality and Social Psychology 2003, 85:453-466.

12. Magee JC, Galinsky AD, Gruenfeld DH: Power, propensity to negotiate, and moving first in competitive interactions. Personality and Social Psychology Bulletin 2007, 33:200-212.

13. Overbeck JR, Park B: Powerful perceivers, powerless objects: Flexibility of powerholders' social attention. Organizational Behavior and Human Decision Processes 2006, 99:227-243.

14. Abele AE, Uchronski M, Suitner C, Wojciszke B: Towards an operationalization of the fundamental dimensions of agency and communion: Trait content ratings in five countries considering valence and frequency of word occurrence. European Journal of Social Psychology 2008, 38:1202-1217. 
15. Cisłak-Wójcik A: Effects of power on person perception: All your boss can see is agency. Social Psychology 2013, 44:139-147.

16. Gruenfeld DH, Inesi ME, Magee JC, Galinsky AD: Power and the objectification of social targets. Journal of Personality and Social Psychology 2008, 95:111-127.

17. Kipnis D: Does power corrupt? Journal of Personality and Social Psychology 1972, 24:33-41.

18. Fitzsimons GM, Shah JY: How goal instrumentality shapes relationship evaluations. Journal of Personality and Social Psychology 2008, 95:319-337.

19. Lammers J, Stapel DA: Power increases dehumanization. Group Processes \& Intergroup Relations 2011, 14:113-126.

20. Gwinn JD, Judd CM, Park B: Less power= less human? Effects of power differentials on dehumanization. Journal of Experimental Social Psychology 2013, 49:464-470.

21. Georgesen JC, Harris MJ: Why's my boss always holding me down? A metaanalysis of power effects on performance evaluations. Personality and Social Psychology Review 1998, 2:184-195.

22. Yap AJ, Mason MF, Ames DR: The powerful size others down: The link between power and estimates of others' size. Journal of Experimental Social Psychology 2013, 49:591-594.

23. Inesi ME, Gruenfeld DH, Galinsky AD: How power corrupts relationships: Cynical attributions for others' generous acts. Journal of Experimental Social Psychology 2012, 48:795-803.

24. Guinote A, Weick M, Cai A: Does power magnify the expression of dispositions? Psychological Science 2012, 23:475-482. 
25. Overbeck JR, Droutman V: One for all: Social power increases self-anchoring of traits, attitudes, and emotions. Psychological Science 2013, 24:1466-1476.

26. Toma C, Yzerbyt V, Corneille O, Demoulin S: The power of projection for powerless and powerful people: Effect of power on social projection is moderated by dimension of judgment. Social Psychological Personality Science 2017, 8:888896.

27. Stamkou E, van Kleef GA, Fischer AH, Kret ME: Are the powerful really blind to the feelings of others? How hierarchical concerns shape attention to emotions. Personality and Social Psychology Bulletin 2016, 42:755-768.

28. Turner JC, Brown RJ, Tajfel H: Social comparison and group interest in ingroup favouritism. European Journal of Social Psychology 1979, 9:187-204.

29. Magee JC, Smith PK: The social distance theory of power. Personality and Social Psychology Review 2013, 17:158-186.

30. Judd CM, Park B: Definition and assessment of accuracy in social stereotypes. Psychological Review 1993, 100:109-128.

31. Fiske ST, Neuberg SL: A continuum of impression formation, from categorybased to individuating processes: Influences of information and motivation on attention and interpretation. In Advances in experimental social psychology.Edited by Zanna MP. Elsevier; 1990:1-74.

32. Fiske ST: Controlling other people: The impact of power on stereotyping. American Psychologist 1993, 48:621-628.

33. Devine PG: Stereotypes and prejudice: Their automatic and controlled components. Journal of Personality and Social Psychology 1989, 56:5-18. 
34. Gonzales $\mathrm{MH}$, Aronson E, Costanzo MA: Using social cognition and persuasion to promote energy conservation: A quasi-experiment. Journal of Applied Social Psychology 1988, 18:1049-1066.

35. Guinote A, Willis GB, Martellotta C: Social power increases implicit prejudice. Journal of Experimental Social Psychology 2010, 46:299-307.

36. Schmid PC, Amodio DM: Power effects on implicit prejudice and stereotyping: The role of intergroup face processing. Social Neuroscience 2017, 12:218-231.

* An important paper investigating the effect of power on implicit bias showing that being appointed to high power enhances implicit prejudice and stereotyping.

37. Fiske ST, Dépret E: Control, interdependence and power: Understanding social cognition in its social context. European Review of Social Psychology 1996, 7:31-61.

38. Goodwin SA, Gubin A, Fiske ST, Yzerbyt VY: Power can bias impression processes: Stereotyping subordinates by default and by design. Group Processes and Intergroup Relations 2000, 3:227-256.

39. Guinote A, Phillips A: Power can increase stereotyping. Social Psychology 2010, 41:3-9.

40. Rodríguez-Bailón R, Moya M, Yzerbyt V: Why do superiors attend to negative stereotypic information about their subordinates? Effects of power legitimacy on social perception. European Journal of Social Psychology 2000, 30:651-671.

* This paper shows the importance of how power is understood when investigating the effects of power on stereotypes and shows that llegitimate leaders pay more attention to stereotype-consistent information.

41. Hall JA, Schmid Mast M, West TV: The social psychology of perceiving others accurately. Cambridge University Press; 2016. 
** This book gives an overview of factors affecting accurate perception of social interaction partners and the downstream effects of accurate interpersonal perception.

42. Galinsky AD, Magee JC, Inesi ME, Gruenfeld DH: Power and perspectives not taken. Psychological Science 2006, 17:1068-1074.

43. Van Kleef GA, Oveis C, Van Der Löwe I, LuoKogan A, Goetz J, Keltner D: Power, distress, and compassion: Turning a blind eye to the suffering of others. Psychological Science 2008, 19:1315-1322.

44. Schmid PC, Kleiman T, Amodio DM: Power effects on cognitive control: Turning conflict into action. Journal of Experimental Psychology: General 2015, 144:655663.

45. Schmid Mast M, Jonas K, Cronauer CK, Darioly A: On the importance of the superior's interpersonal sensitivity for good leadership. Journal of Applied Social Psychology 2012, 42:1043-1068.

46. Byron K: Male and female managers' ability to read emotions: Relationships with supervisor's performance ratings and subordinates' satisfaction ratings. Journal of Occupational and Organizational Psychology 2007, 80:713-733.

47. Momm T, Blickle G, Liu Y, Wihler A, Kholin M, Menges JI: It pays to have an eye for emotions: Emotion recognition ability indirectly predicts annual income. Journal of Organizational Behavior 2015, 36:147-163.

48. Schmid Mast M, Darioly A: Emotion recognition accuracy in hierarchical relationships. Swiss Journal of Psychology 2014, 73:69-75.

49. Zhong Y, Zhang S, Chen Y: Differences of interpersonal sensitivity between highpower people and low-power people. Journal of Clinical Psychology 2013, 21:62-65. 
50. Walter F, Cole MS, van der Vegt GS, Rubin RS, Bommer WH: Emotion recognition and emergent leadership: Unraveling mediating mechanisms and boundary conditions. The Leadership Quarterly 2012, 23:977-991.

51. Hall JA, Schmid Mast M, Latu I-M: The vertical dimension of social relations and accurate interpersonal perception: A meta-analysis. Journal of Nonverbal Behavior 2015, 39:131-163.

** A meta-analysis looking at the controversial results about power and accurate interpersonal perception showing that there is no relation between power and interpersonal accuracy with the exception of high power people remembering more information about others than the low power individuals and high SES individuals making more accurate inferences about others.

52. Sassenberg K, Ellemers N, Scheepers D: The attraction of social power: The influence of construing power as opportunity versus responsibility. Journal of Experimental Social Psychology 2012, 48:550-555.

53. Schmid Mast M, Jonas K, Hall JA: Give a person power and he or she will show interpersonal sensitivity: The phenomenon and its why and when. Journal of Personality and Social Psychology 2009, 97:835-850.

54. Galinsky AD, Rucker DD, Magee J: Power and perspective-taking: A critical examination. Journal of Experimental Social Psychology 2016, 67:91-92.

55. Blader SL, Shirako A, Chen Y-R: Looking out from the top: Differential effects of status and power on perspective taking. Personality and Social Psychology Bulletin 2016, 42:723-737.

56. Magee JC, Galinsky AD: 8 social hierarchy: The self-reinforcing nature of power and status. Academy of Management Annals 2008, 2:351-398. 
57. Tost LP: When, why, and how do powerholders "feel the power"? Examining the links between structural and psychological power and reviving the connection between power and responsibility. Research in Organizational Behavior 2015, 35:29-56.

58. Blader SL, Chen Y-R: Differentiating the effects of status and power: a justice perspective. Journal of Personality and Social Psychology 2012, 102:994-1014.

59. Casciaro T: Seeing things clearly: Social structure, personality, and accuracy in social network perception. Social Networks 1998, 20:331-351.

60. Marineau JE, Labianca GJ, Brass DJ, Borgatti SP, Vecchi P: Individuals' power and their social network accuracy: A situated cognition perspective. Social Networks 2018, 54:145-161.

61. Sherman GD, Lerner JS, Renshon J, Ma-Kellams C, Joel S: Perceiving others' feelings: the importance of personality and social structure. Social Psychological Personality Science 2015, 6:559-569. 